\title{
The New Paradigm Is Already Here:
}

\section{The Practicing of Prototypes of Future through Vertical Alignment}

\author{
Kirsi Hakio \\ Aalto University \\ kirsi.hakio@aalto.fi
}

\begin{abstract}
This paper examines how abstract concepts of alignment, such as moving between different levels of attention, were rendered visible and concrete in a nature-tourism context. The case study is a project designed to construct a prototype of a possible future culture rooted in care and awareness-based cocreation. To support the concept of vertical alignment, the paper includes an introduction to the literature on care ethics and tangible perspectives on the connections and relationships between self, others, and the larger whole. The research findings are examined through the analytical lenses generated during the research process with the idea of following how the internal abilities related to moving between different levels of attention influenced the formation of the visible outcomes and thus the emergence of the new. In light of the current global pressures for change toward human and planetary sustainability and the capacity-building needs emphasizing new inner postures and abilities to act from broader ecosystem awareness, the paper provides real-world examples of what
\end{abstract}


new ways of becoming with the world could look like in practice, as everyday activities and choices.

\section{Keywords}

prototypes of future; vertical alignment; capacity building; care ethics; case study

\section{Introduction}

Humanity has reached a point where, if we are to co-create sustainable futures in which all beings can flourish, we will need new mindsets and internal postures to face the challenges before us, navigate uncertainty together, and more forward collectively (Haraway, 2016; Irwin, 2015; Puig de la Bellacasa, 2017). A recent paper for UNESCO's Futures of Education initiative highlights building that capacity for "learning to become with the world," coupled with developing capabilities to "imagine alternative ways of living with the Earth." Both will be critical for our continued survival (UNESCO, 2020). Many authors have argued that such a transformation in our mindset and posture of being in the world requires a radical paradigm shift (UNESCO, 2020; Irwin, 2015; Scharmer, 2016; Tronto, 2013; du Plessis, 2015).

Shifting individual-level and collective postures and mindsets toward more aware and sustainable ways of being and becoming has been the focus of the work of Otto Scharmer and his colleagues for decades (Senge et al., 2004). As a result of those collaborations, Scharmer has developed an approach to awareness-based systems change, Theory $\mathrm{U}$, which provides a transformation framework, process, and practical tools for bringing about such change (Scharmer, 2016; 2018). Theory $\mathrm{U}$ is grounded in the view that form follows consciousness, meaning that the interior condition of individuals in a social system, the source condition, determines the quality of people's actions, and thus gives rise to and co-shapes how the visible outcomes and practical results of that system unfold (Scharmer, 2018, p. 16; Scharmer, 2016, p. 94; Scharmer \& Pomeroy, 2019). Thus the process of Theory U focuses specifically on this source condition and teaches participants to transform perception, transform self and will, and transform action (Jaworski et al., 2004). These transformations entail adopting new inner postures and consciousness, through which people practice alternative ways to listen, see, and sense themselves, along with new ways to interact with others and the world. 1 Through this process the participants gain the ability to act from the inner wisdom that arises from the natural, innate connectedness to the larger whole (the ecosystem, the Earth, and the sources of life). These thoughts on the larger whole are discussed in more detail in the next section.

${ }^{1}$ For details about the aims, processes, and tools of Theory U, see Scharmer's work (2016, 2018) and the Presencing Institute web page: https://www.presencing.org/aboutus/theory-u. 
One key element of the transformation journey provided by Theory $\mathrm{U}$ is to increase vertical alignment abilities and capacity.

Vertical alignment is about moving between different levels of attention. It is a way of accessing one's personal experience and then exploring it from distinct perspectives (Scharmer \& Pomeroy, 2019). The "inner movement" of vertical alignment is related to Scharmer's definition of vertical literacy $(2020,2019)$ as the capacity to connect with the knowing that arises from deeper levels of consciousness (Scharmer \& Pomeroy, 2019). Building on the idea that form follows consciousness, vertical literacy highlights how modern education needs to pay attention to capacity building that focuses on people's ability to operate from the sources of social action, individually and collectively (Scharmer, 2019)-in other words, moving from habitual awareness to more relational and empathic viewpoints, and eventually into a generative state of ecosystem awareness where it is possible to sense and actualize future potentials (Scharmer, 2018, pp. 3639). Thus the inner movement between different levels of attention that takes place in practicing vertical alignment can be seen as a vehicle that helps put into practice these ideas of vertical literacy. ${ }^{2}$ Here, vertical alignment is defined as a three-step-movement that teaches people how to (1) enhance their ability to align their actions with their inner wisdom, (2) extend that alignment to others in the ecosystem, and (3) ultimately align with the larger whole. These aims of vertical alignment and principles of vertical literacy respond to the needs that UNESCO outlined for learning new ways to be and become with the world and our planet.

While Theory U provides a framework and tools for building vertical literacy (Scharmer, 2019; 2020, p. 7), there has been little research into what the related alignment abilities and capacity might mean in practice (e.g., as part of research and development processes). This paper contributes to this gap by presenting a case study in which practices of moving between different levels of attention were part of a development project in the context of nature tourism; its goal was to develop a new work and service culture based on co-creation and care. These intentions were seen as a way to devise and explore ideas for a prototype of a possible future culture (see Manzini, 2015) and thus experiment with alternative ways of becoming with the world. Inspired by the ideas of Theory U-specifically, that form follows consciousness and vertical literacy-the guiding question for this paper is:

How do the internal abilities related to moving between different levels of attention, such as being aware of one's own awareness and shifting one's lenses of perception, affect the formation of visible outcomes, actions, and practices, and thus the emergence of the new?

2 For more information on vertical literacy, see the Matrix of Social Evolution (Scharmer, 2018, pp. 36-37) and the map of Four Stages of Systems Evolution (Scharmer, 2019). 
To anchor the study, I begin by introducing the literature on care ethics. The field of care ethics offers an opportunity to view the world beyond humancentered and market-driven thinking and paradigms. It supports the practice of vertical alignment by providing tangible perspectives on the connections and relationships between self, others, and the larger whole. I then present a case study for which research material was collected and analyzed using a constructive design research approach. The research findings are then presented through the analytical lenses generated in the process, which highlight the contribution of this paper: real-world examples of what abstract concepts like vertical alignment, moving between different levels of attention, and new ways of becoming with the world could look like. After this discussion, the research findings are discussed in light of the capacity-building needs outlined above and in connection with creating prototypes of possible futures as a means of responding to the current global pressure for change toward human and planetary sustainability.

\section{Grounding in the Literature}

This section offers a brief introduction to care ethics and how it relates to the concept of vertical alignment and the practice of its three-step-movement.

\section{Care as a Ubiquitous and Unavoidable Force of Life}

The care ethics field provides an opportunity to look at our relationships with and attitudes toward ourselves and others-people, non-humans, nature, and the Earth (see, e.g., Puig de la Bellacasa, 2010, 2017). Like the essence of vertical alignment described above, care ethics entails engaging in a three-step movement between different levels of attention. These can be, for example, perception of the self, of the surrounding context, and of a broader life-sustaining whole.

\section{Perception of the Self}

According to the principles of care ethics, a worldview based on individualism and detachment is an illusion. Human beings are always dependent on others; care is both given and received, even if it goes unnoticed (Hankivsky, 2004; Mol, 2008; Tronto, 2013). However, the event of care (such as that perceived in caregiving) is not always a direct interaction between two parties; rather, it is a movement that returns to the giver in various forms (Puig de la Bellacasa, 2010; Tronto, 1993, 2013). In modern Western societies individuals often think of themselves as autonomous, even though many no longer cultivate their own food, sew their own clothes, bury their own dead, etc. (Mol, 2008, p. 4). Such silent dependency on others can be easily overlooked unless it is specifically pointed out. Through the concept of care ethics, it becomes possible to reconsider this distorted perception of oneself and one's connections with the rest of the world. 


\section{Interconnections with Non-Human Worlds}

The themes of individuality and detachment come to the fore more broadly in discussions of interconnectedness and relationships between human beings and nature (see, e.g., Puig de la Bellacasa, 2010, 2017; Zylstra et al., 2014). These are easily understood concepts in the abstract; when embodied in person, however, they yield eye-opening experiences-for instance, in wilderness experiences (Aaltola, 2015) or ecological self-practices as experiences of deep interconnectedness with all life (Macy \& Brown, 2014). Western societies and lifestyles are built in a way that masks people's interconnectedness and dependency on non-humans (Zylstra et al., 2014). For example, we cannot generate the substances needed for physiological survival without natural systems and the elements they are composed of, such as fresh water and oxygen. Puig de la Bellacasa (2010) demonstrates the translation of her take on care ethics into tangible form through the everyday practices of permaculture, where care of Earth and care of people go hand in hand. Viewing these practices of permaculture as actions of care that transform the way in which we feel, think, and engage, she describes how individual practices are closely related to collective ones. In the context, care can be seen as an act that creates relations among humans, non-humans, and the Earth, thus creating relationality (Puig de la Bellacasa, 2010, p. 164).

\section{The Life-Sustaining Larger Whole}

Finally, when one considers alignment and connectedness to a broader lifesustaining source, care can be seen as a phenomenon without which there would be no life. From this perspective, care is present in every movement, action, and interaction; the biosphere would not exist without an all-encompassing, ongoing cycle of care. Joan Tronto defines this essentiality of care as "a species activity that includes everything that we do to maintain, continue, and repair our 'world' so that we can live in it as well as possible." This interconnected world "includes our bodies, ourselves, and our environment, all of which we seek to interweave in a complex, life-sustaining web" (Tronto, 1993, p. 103). This take on care goes beyond questions of giving or receiving it, even beyond viewing care as a movement that returns to its giver in various forms. It proceeds from the premise that humans and non-humans are not competitors but cohabitants who coexist with the ecosystem and are highly dependent on recognition and appreciation for the other. Since care is present wherever there is life, it is ubiquitous in a profound sense (Yeandle at al., 2017) and unavoidable (Puig de la Bellacasa, 2012).

\section{Care and Alignment Practices}

Aligning with such an all-encompassing, life-sustaining web and whole requires of its experiencer a shift of internal mindset and posture, along with the capacity to connect with the knowing that flows from deeper levels of consciousness (see 
Scharmer \& Pomeroy, 2019). Joseph Jaworski's research on synchronicity (2011) usefully describes such a shift of awareness in more detail and can serve here to complement the views expressed in the care ethics literature. He uses language such as "choice," "belief," and "strong personal sense" to describe the inner posture upon which access to tacit knowledge of "vital forces that are larger than our selves" (Jaworski, 2011, p. 88) is based. Hence, accessing deeper knowing about phenomena such as care is not a rational process of observing the visible world but a worldview, and it involves a deep personal belief that "there is an underlying intelligence within the universe" (Jaworski, 2011, p. x). Practicing such alignment requires surrender and trust also, where the former refers to an act of opening oneself to experiencing care in its diverse forms. Many have highlighted how an inner state of surrender and open will are keys to experiencing phenomena that are invisible to the eye (e.g., Jaworski, 2011; Scharmer, 2016; Akama, 2018; Macy and Brown, 2014). The case study presented here reveals a fuller picture of how such experiences of surrendering and alignment may look in practice.

Before delving into it, however, I want to emphasize that it is a choice to perceive the world through the lenses of care ethics or to engage in a movement between different levels of attention. Only by building our capacity for selfawareness can we access this choice, as Dayna Cunningham (2018) has pointed out:

Every moment is a crossroad-or parting of the ways-leading to a choice. The question is [whether we are] aware of the moment of choice happening inside us, as well as the tone and nature of our mindset when making the choice. These are basic principles of selfawareness and consciousness of being present in a moment.

When considering new ways of becoming with the world or acting from an evolved inner posture, building the capacity to identify these moments of internal choice is central.

\section{Case Study}

The case study's setting was the nature-tourism destination Elisaari. An island on the archipelago of southern Finland, Elisaari is partly a nature reserve and is owned by the City of Helsinki. Running a nature-tourism business here, a local entrepreneur couple work as custodians of this destination with the freedom to develop the area as they wish. In addition to various nature-tourism services, they offer services for boaters and accommodations, as well as facilities for retreats, camps, and training. They hire outside help in the form of seasonal workers in the summer peak season, but otherwise they look after the facility themselves.

The starting point for the collaboration between this couple (hereinafter referred to as entrepreneur $\mathrm{S}$ and entrepreneur $\mathrm{P}$ ) and a design researcher (the author) was a shared interest in awareness-based transformation, experimental 
and co-creative development approaches, and the prototyping of alternative future paradigms. The initial intention of the project, which began in late 2016, was to carry out small-scale experiments using new ideas developed with the local community to prototype a new future work and service culture-one grounded in care and awareness-based co-creation, encompassing nature and all non-humans. To support this, the entrepreneurs set specific guiding values as a jumping-off point for the collaboration process: discovering nature, compassionate living, welcoming others, creating beauty, developing "heart intelligence," new ways of working with money, developing awareness / inner work, co-creation, artistic expression, and working with rhythms (of life). Later, in 2017, the project's scope expanded to establishing a community around these ideas; the entrepreneurs had long-term ambitious visions and dreams of building a new local center for education where a paradigm of care and awareness-based co-creation could be studied and practiced. In this context, a central development influencing the project was the unexpected sale of a nearby old village school, which the entrepreneurs acquired, renovated, and expanded in 2017-2018. In line with the guiding values and intention, the school was named Villa Sofia, to represent "a house of wisdom, allowing the inner wisdom of the co-creators to be refined into wise deeds" (Villa Sofia Facebook page, March 2019).

\section{The Research Approach and Collection of Data}

The research approach is grounded in constructive design research (Koskinen et al., 2011), which is based on constructing knowledge in and through a design process. The emphasis is on tangible and embodied practices of making, experimenting, and prototyping in parallel with reflective conversation with the people involved about the context and the materials to be used (see Eriksen, 2012; Schön, 1983). The process was also influenced by Theory U, incorporating a framework of five movements: co-initiating, co-sensing, presencing, co-creating, and co-evolving (Scharmer 2016, 2018) (figure 1). This awareness-based approach was used in encounters and workshops to promote alignment and connecting to self and to the essence of the present moment. Thus presencing is positioned in the process diagram as a major steering and supporting element for the entire process. 

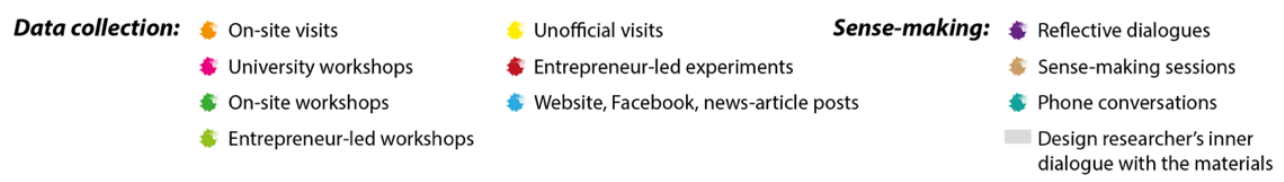

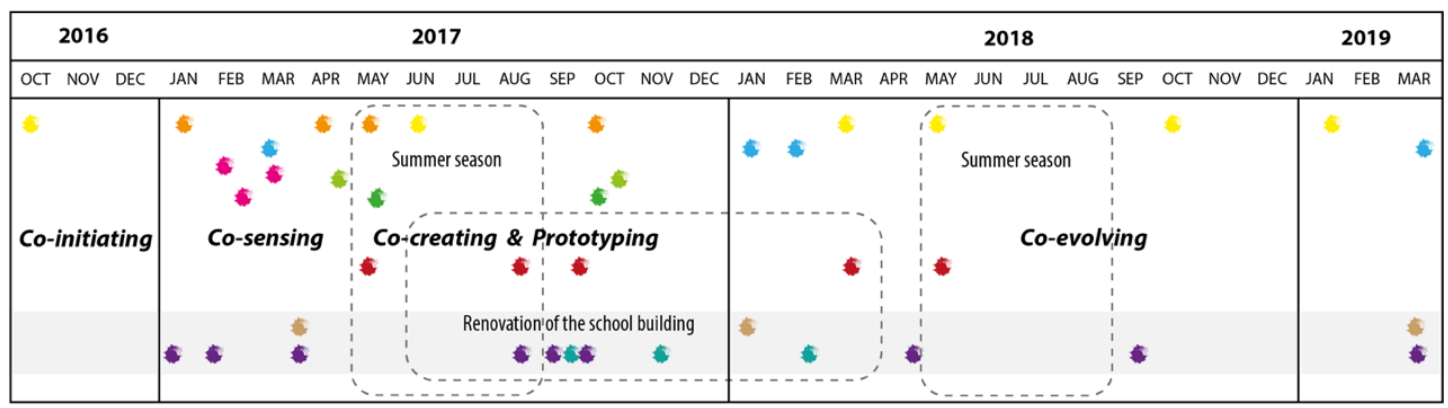

Presencing

Figure 1: Illustration of the process's overall structure, along with its data-collection and sense-making steps.

Research was conducted for more than two years. This paper looks in particular at the prototyping stage and how movement between the different levels of attention manifested itself in the process of co-creating the new culture. Thus the scope of this paper is limited accordingly; however, the reader may benefit from a broader picture, so Annex provides details about the whole datacollection and sense-making process: who was involved and the purpose, outcome, and impact of each activity.

\section{Formation of the Analytical Lenses}

As Figure 1 and Annex show, the process yielded multivalent data and other information, as is typical of constructive design research. To facilitate synthesis and broader understanding, the information was analyzed by categorizing and grouping its various elements both physically and digitally (figure 2).

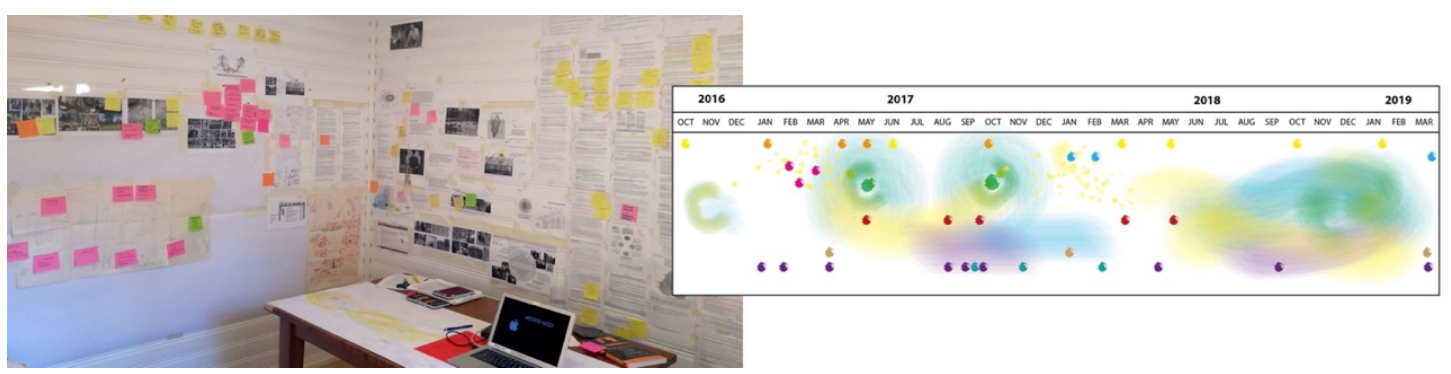

Figure 2: The varied and ambiguous material collected was analyzed by grouping elements on a wall (at left) and through visualization cycles (both hand-drawn and digital).

Such categorization activities are not purely intellectual ways of analyzing the data in a systematic manner. As Halse and colleagues have pointed out, this type of analysis calls for "attention to the practitioners' own creative being in the situation" and "a full-bodied, environmentally and socially dependent process 
expressed in actions as well as words" (Halse et al., 2010, p. 148). Throughout the process, the design researcher engaged in reflective dialogue and a joint sensemaking process with the entrepreneurs to create meaning together. (See Figure 1 timeline and Annex.) The dialogical approach shaped the design researcher's own analysis and synthesis, as well as her inner dialogue with the materials, thus helping to keep the process relevant for the local partners and the community (Krogh \& Koskinen, 2020).

Crucial insights emerged in 2019 when the design researcher saw connections between the literature on care ethics and vertical alignment practices (conducted in the workshops, see Annex), and a multilayered visualization of the essence of the island made by entrepreneur S. In March 2017, entrepreneur S had placed a sheet of translucent baking paper atop a drawing in which she had created a map of the island and its nature-tourism services. The baking paper depicted a second map, informed by her background in Rudolf Steiner's anthroposophy. The map showed tree species growing on the island and their differences in tone, essence, and meaning, including more spiritual aspects (figure 3). The two layers represent different worldviews and perceptions of reality; each can be perceived and experienced in accordance with how the perceiver/experiencer is oriented to viewing lived experience. In other words, they require the perceiver/experiencer to use different levels of attention.
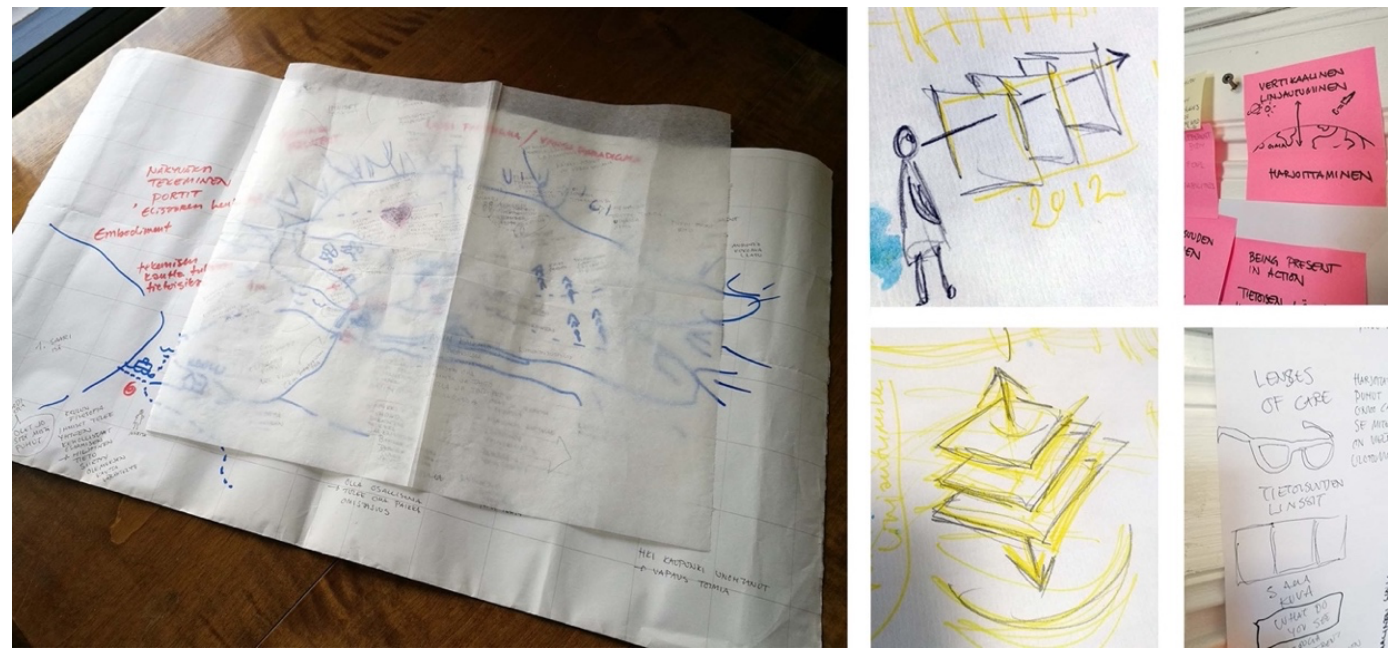

Figure 3: The original drawing by entrepreneur S in 2017 (left); the design researcher's follow-up visualizations of a multi-layered reality experience in 2019 (right). These became the underpinnings of the analytical lenses.

These insights triggered the idea of exploring and arranging miscellaneous materials and information through different experiential layers, corresponding to the three-step movement of vertical alignment and the three distinct ways of perceiving and experiencing oneself and the world as articulated by scholars of care ethics. By combining the two perspectives, the design researcher identified common themes for the analytical lenses (figure 4). 

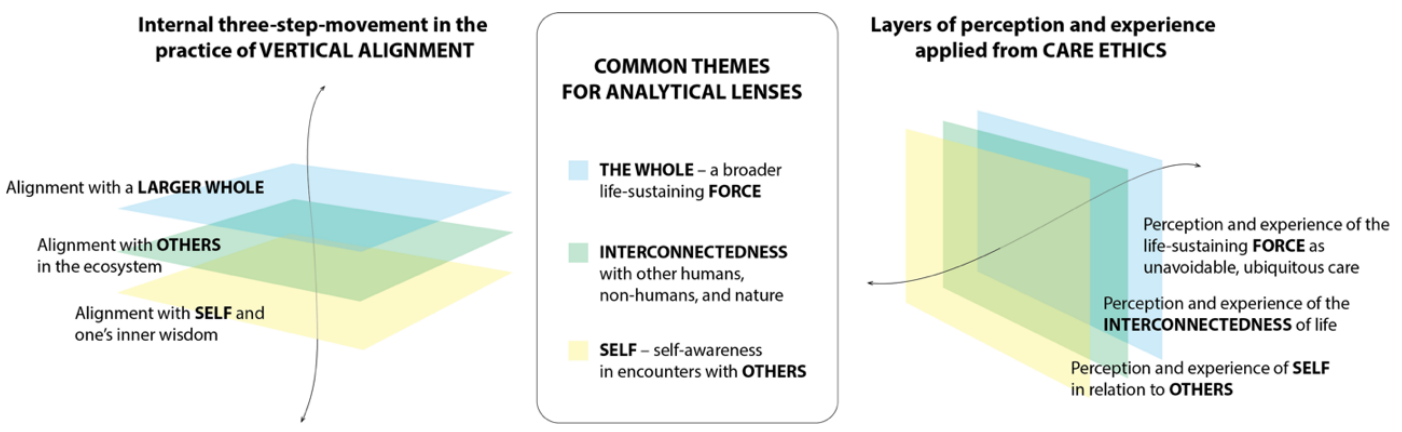

Figure 4: Analytical lenses for exploring the research findings through movements between three levels of attention: the alignment with self-awareness in encounters, the alignment with interconnected perspectives, and the alignment with the larger whole.

The following three sections address the findings as viewed through the three analytical lenses and highlight how exercising internal movement across the corresponding levels of attention was manifested in the project and the process of co-creating the new culture. Therefore each section also attests to how the project's intention and guiding values were translated into practices and outcomes.

\section{The First Lens: Everyday Encounters}

This section presents the main findings of how alignment with self was manifested in everyday encounters (figure 5). These findings relate to the entrepreneur couple's personal experiences, to workshop practices with local stakeholders, and to the seasonal employee recruitment process and its outcomes. Since more detailed descriptions of the last two have already been presented elsewhere (see Hakio and Mattelmäki 2019), they are discussed here only briefly.

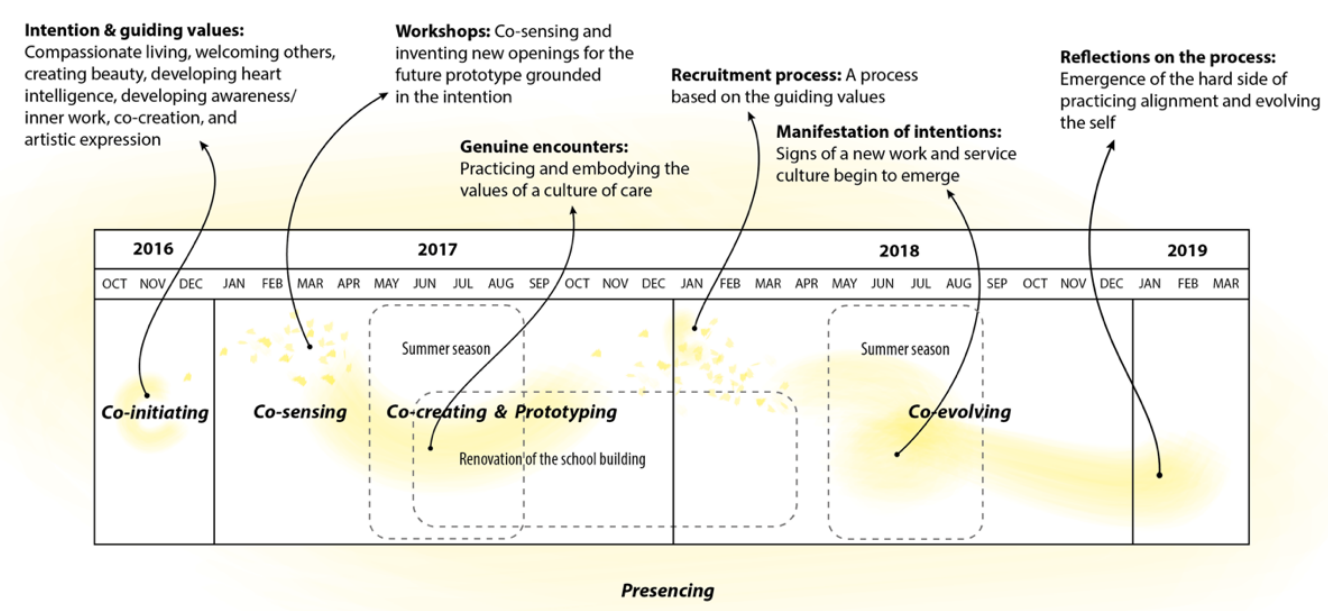

Figure 5: Illustration of the main findings related to the theme of everyday encounters. 
The workshops took place at the beginning of the project in 2017 (figure 1, also Annex and university workshops), when 30 local stakeholders gathered together with the entrepreneurs to co-sense and conceive new openings for service concepts and collaboration. In all the workshops, a self-awareness element was embedded in the exercises. The aim of these exercises was to establish favorable conditions for fruitful encounters and discussions among the participants by asking them to first focus on "scanning" their inner state of being and thereby becoming aware of their own internal posture toward the groupwork. This alignment with oneself was practiced, for example, through mindfulness exercises and experimental visual tools. As a result of the search for new openings, one of the themes raised was the idea of a "unifying encounter" both between people and with nature, which was repeated in all of the ideas produced in the workshops. (See Annex and entrepreneur-led experiments.)

One example of how these unifying encounters occurred later can be found in an experiment conducted in 2018 to reform the island's annual recruitment process for seasonal employees. In a nutshell, the entrepreneurs wanted to give the new employees space to interpret, embrace, and implement the guiding values of the place as they wished. This co-creative approach allowed the employees to self-direct and realize their own internal visions, and thus manifest a caring work and service culture in various forms (see Hakio \& Mattelmäki 2019). The impacts of the practices and atmosphere created by the employees were experienced by the customers, which in turn generated a lot of positive customer feedback during the season.

The following findings are based on the design researcher's observations of the entrepreneurial couple's activities at different stages of the project, as well as their own accounts of their experiences. Both entrepreneurs were already inherently embodying the co-creative and caring culture they envisioned in their interactions with customers, partners, and employees. This culture was particularly visible at mealtimes: all site visits and the field notes attest that it is customary for the entrepreneurs and the facility to invite all those who are present, be they employees, renovation workers, and even occasional visitors, to take their meals at the same table. This practice led to gatherings where work matters and current burning issues were sometimes discussed, but also to discussions about people's own lives and life paths. This atmosphere of openness and mutual encounters, in which one person is genuinely seen and heard by others, naturally extended to how people worked together. This approach yielded encouraging results. For instance, observations from all of the visits during the renovation of Villa Sofia revealed that the site's personnel and renovators exhibited flexibility and willingness to resolve challenging situations related to the renovation work together (figure 1).

Entrepreneur S personally experienced these sometimes very small gestures of pausing together for a moment and sharing coffee or eating together as "a means of empowering both the individual and the community," according to comments from the August 2017 reflective-dialogue session. Entrepreneur P 
extended this idea, reflecting on the service and work culture that the two want to foster in a broader sense by analogy to a service-design approach:

The existing services are being built like a theatrical set. There is a structure that guides you, saying, "When you act like this, you are safe." But what should happen to make you feel like you are not working in such scenery, producing services and experiences in accordance with the service instructions? Here, the encounter takes place on an equal footing without service instructions. Just a real, genuine encounter.

Although these examples of unifying and genuine encounters do not directly indicate the ability of those involved to align with themselves in those encounters, they do provide valuable insights for manifesting a co-creative and caring culture, and thus prototyping alternative ways of becoming. In particular, they emphasize encounters in which the internal posture of the people involvedin other words, the source conditions-indicates appreciation and respect for each other. However, the last two examples are directly linked to alignment with self (and practicing self-awareness) in encounters.

Entrepreneur S reported on her encounters with clients by practicing the internal movement of self-awareness in summer 2017. She spoke about how she had faced three angry customers, each dissatisfied in his or her own way. She detailed how, after peaceful resolution of the situation with the customer, each situation gradually became less threatening, eventually ending well, either at that moment or the next day. She then reflected upon the experience, noting that it took courage to engage face-to-face with these clients, who were either drunk or otherwise in a highly agitated state.

I was taught that if I stay in my own center and face the other without fear and without letting any of my internal triggers react, so that I won't escape or attack, then we are able to have a genuine encounter with whomever. It worked with the drunk too: I looked him in the eyes the whole time. I recognized a change in myself. I have worked with myself. When you stay aligned in your own center, such [an] encounter arises. (Reflective-dialogue session, September 2018)

Later, in 2019, she reflected on her experience with social entrepreneurship. During the process of renovating Villa Sofia, she had encountered similar opportunities for practicing alignment when working with marginalized young people and in apprenticeship relations:

There are always situations where you just want to stop and throw your gloves on the counter, when the shadows of social entrepreneurship emerge and you feel like there is not balance in the giving and receiving. Developing intelligence of the heart seems to be the clearest, visible work that is offered to us as humanity in this time. But it has been noticed here how it is not 
philosophical contemplative work but, rather, quite raw and cruel work! (Reflective-dialogue session, March 2019)

Her experiences reveal that each moment carries an opportunity to choose one's quality of becoming and one's way of developing heart intelligence, echoing Dayna Cunningham's words above. They also describe times when challenges or disruption arise, and point out the difficult side of practicing alignment with oneself and others.

\section{The Second Lens: A State of Interconnectedness}

Since the context of the case study was nature tourism, nature was a key factor in all the activities at the location. The purpose of the analysis was to identify moments, experiences, and manifestations of the guiding values related to the state of interconnectedness and to describe what it might mean to perceive and experience reality through this lens (figure 6).

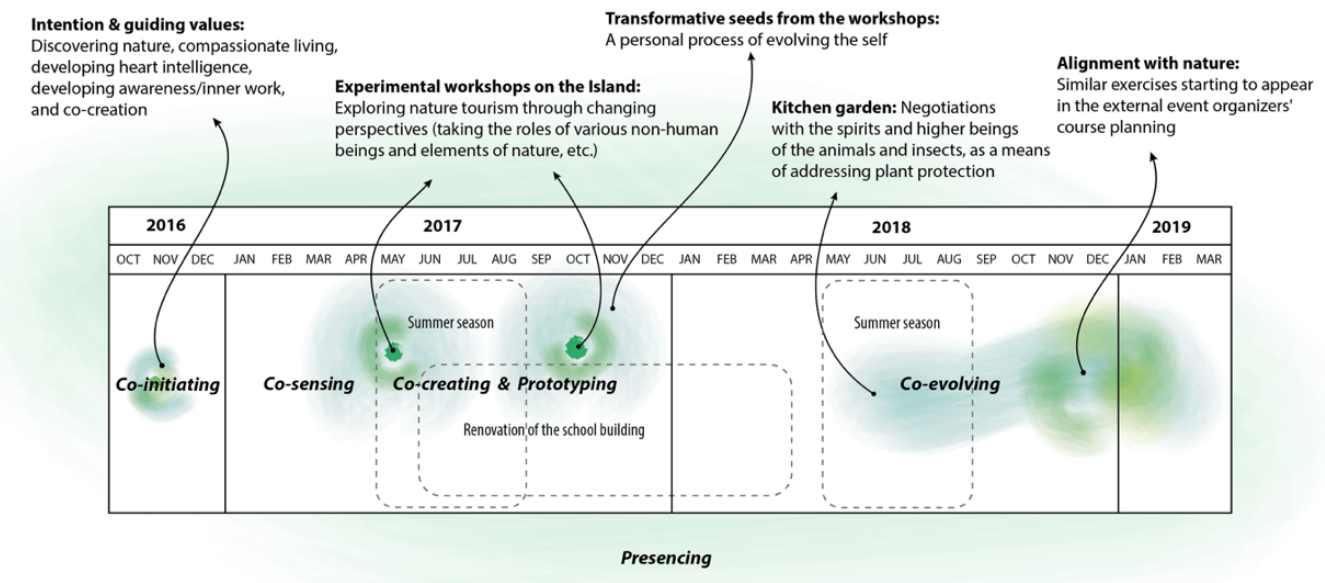

Figure 6: Illustration of the main findings related to the theme of interconnectedness.

An example can be found in one small, nearly imperceptible gesture by the entrepreneurs to protect the plants in their kitchen garden. They noted at the reflective-dialogue sessions of August 2017 and March 2019 that, instead of using pesticides, they communicate with the insects and other animals on socalled internal levels and talk with them (figure 7). Similarly to how the Runa people of the Amazon (Kohn, 2013) spoke to the spirit and higher being of a jaguar pilfering the villagers' food, they engaged in discussions with the spirits of deer and snails on the island about where to obtain food and who needs what. These conversations, which have their roots in the entrepreneurs' life-centered and anthroposophic worldview, sometimes took the form of meditation, and sometimes involved simply talking to the beings. The core idea is not new in the history of our planet; a similar worldview and conception of reality-in which all living things are seen as connected to the same life energy and experience of 
living - can be found in indigenous cultures, past civilizations, and philosophical ideas. $^{3}$
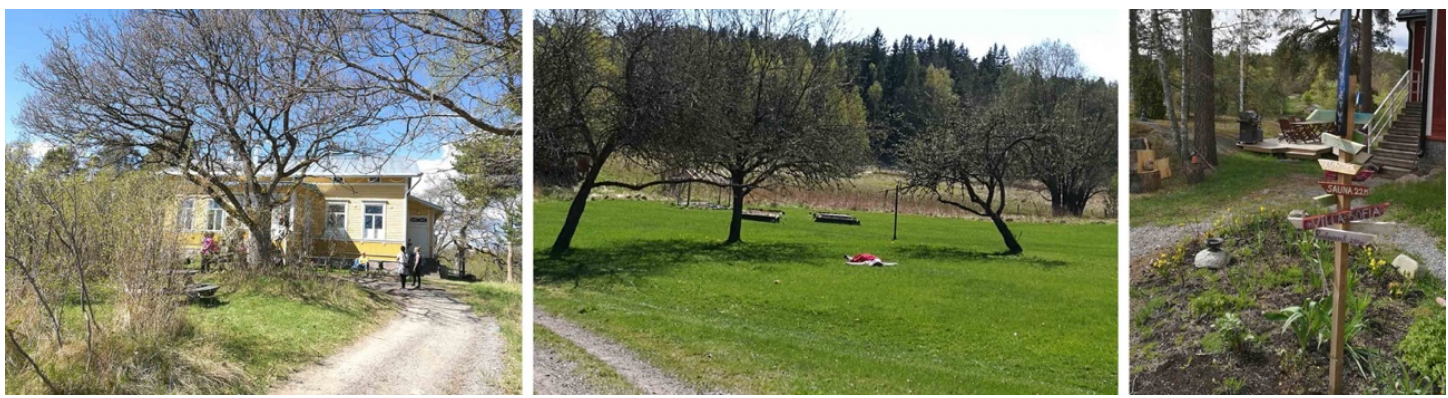

Figure 7: The kitchen garden locations near the island's main building and later at Villa Sofia.

"Negotiations" with the spirits of the animals took place in both places through meditation and conversation.

Switching perspective and gaining a broader awareness of interconnectedness were deliberately explored, particularly at the on-site workshop in October 2017, where nature tourism was examined from the perspectives of non-humans and nature. In this workshop with 16 participants, manmade nature-tourism services were challenged through alignment and roleplaying exercises. Some of the participants played the part of nature tourists, while others - to the best of their ability - took on the role of local animals, a protected oak tree, or a plant. In addition, some played a nature spirit, a boulder, or a figure from the history of the island. This activity brought a completely different time scale and perspective, as well as a holistic approach, to the exercise. Since the study was exploratory and followed a learning-by-doing ethos, and because the emphasis on synthesis between findings from the care ethics literature and vertical alignment practices emerged only as the process progressed, the long-term experiences of participants were not systematically followed. That said, some of their immediate reflections on alignment experiences are reported on in Annex and addressed in more detail in a separate publication, on the co-creation phases of the case study (Hakio \& Mattelmäki, 2019).

However, consistent with Puig de la Bellacasa's arguments (2010) on seeing permaculture as a seed that eventually, through hands-on practices and personal

${ }^{3}$ In Eastern traditions such as Shinto, nature is seen sacred. The sun, the stars, the rocks, the animals, and all creatures on Earth, including humans, are seen as “one.” E.g., Thomas Kasulis's study of Japanese philosophy has delved into these topics (introduced in Akama, 2012).

According to the ancient Greek worldview, all living things — humans, animals, and plants have a soul. In one of Plato's dialogues, Timaios (30b,c,d), he explains that Cosmos is a living creature of which all other living creatures, severally and generically, are a part. The philosophical theory of panpsychism also holds that consciousness is a fundamental and ubiquitous quality of the world. Simply put, contrary to the mechanistic worldview, the world is awake (Seager 2020). 
engagement, generates transformation, a seed of change was sown at this workshop - a seed that later began to germinate within entrepreneur $\mathrm{S}$ as an intimate, inner experience of connection with nature. At one of the later reflection discussions, in September 2018, she shared how these experiments had begun to live in her, in a process of personal evolution. As with the peeling of an onion, ever newer and deeper insights and levels of experience kept opening in her connection with nature and in her way of being as a part of the whole.

Musing on this kind of self-development through nature experiences more generally, she stated at the March 2019 reflective-dialogue session that she had noticed how almost every course organizer arriving at Villa Sofia had adopted similar approaches to connecting with nature as a part of the relevant course program, be it through drumming, walking in nature, making art, or exercising mindfulness in the woods. The following extract from a social-media post by one course organizer is illustrative:

Some pictures from a conscious moment in the forest during our co-created exploration in Villa Sofia. Sensing the environment in silence, the wind sweeping through my being, hanging on the branches, finding a safe space inside the green inviting the sun to my face. Finally laying down in the snow to watch the sky. Funny how I still feel the memory in my body. It just did so good to me. The others felt the same, our journeys provided important insight. Nature teaches us. (Facebook post, March 24, 2019)

Many additional examples could be cited that indicate how the intention of prototyping a new future culture, including new ways of being and becoming with the world, had begun to live its own life in those who had co-created it and in those who came to experience it.

\section{The Third Lens: Life-Sustaining Force}

The final lens is grounded in a worldview and perception of reality wherein life is seen as based on an all-encompassing supportive source that maintains living connections among all lifeforms. Figure 8 illustrates how the findings related to this lens are positioned on the project timeline.

Again, early care ethics literature articulates central themes for purposes of this lens well-trust and surrendering as a form of letting go-for example, letting go of fear and control. The process of renovating Villa Sofia offers an excellent example of how these themes became visible. When the local school building was put up for sale unexpectedly, the entrepreneurs knew that any efforts to find sufficient financial resources would have to start from scratch; however, the they decided that purchasing the building made sense because it dovetailed with their vision of creating a physical center where their goal of studying and practicing a new paradigm based on care and awareness-based cocreation could be realized. Although various business solutions and support 
funding eventually materialized, the whole renovation process required the entrepreneurs to exercise tremendous and constant trust.

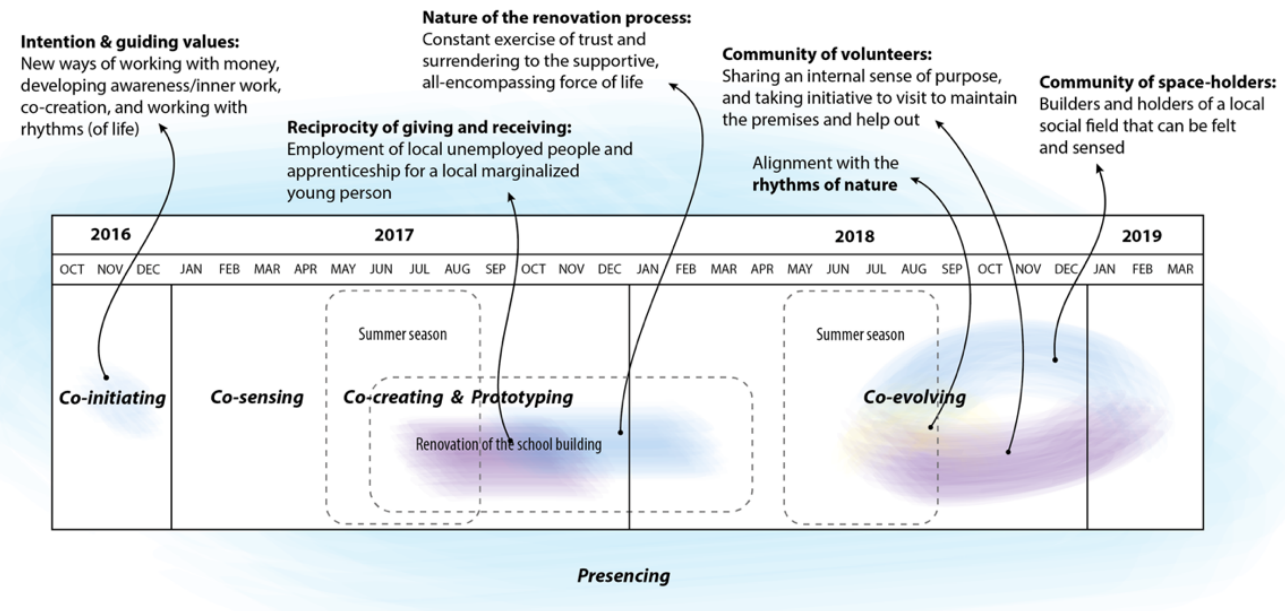

\section{Figure 8: Illustration of the main findings related to the theme of surrendering to the all-encompassing supportive and life-sustaining force.}

With a mechanistic worldview, these events could be read as coincidences. However, they can also be interpreted by looking at synchronicities. Jaworski describes these moments as events wherein things come together unexpectedly, in an uncontrolled and almost unbelievable way, and he cites C. G. Jung's definition of the term "synchronicity," which refers to "a meaningful coincidence of two or more events, where something other than the probability of chance is involved" (Jaworski, 2011, p. xi). At the September 2018 reflective-dialogue session, both entrepreneurs pointed out that their way of doing things, might, from the standpoint of the prevailing market-driven paradigm, seem adventurous, unprofitable, and at times even reckless, but they emphasized also that their decisions were based on an unshakable inner trust in the supportive nature of life, as well as on their personal beliefs, choices, and abilities to align with a larger whole.

Entrepreneur S reflected that in the renovation process, "even if it is made a bit like a jigsaw puzzle, [and] there might not always be enough supplies, or there are no materials, we always start from the premise of what is beautiful" (reflective-dialogue session, March 2019). In addition, both entrepreneurs noted that, in the end, building materials had always been found in a suitable quantity or were even obtained at no cost because they were someone else's surplus goods. They also remarked that suitable renovators appeared in their life whenever needed. And in accordance with the synchronicities of life, reciprocity was achieved in these encounters, enabling them to hire local unemployed people and educate one local marginalized young person in a new profession, through apprenticeship, in the course of the renovation process.

In line with the intention for the project, to build a community, a community of like-minded people indeed began to emerge and gather at Villa Sofia in 2018. 
One group consisted of "volunteers" who had found their way to the location through the guidance of their "internal sense of purpose." This group included women who wanted to spend time at Villa Sofia and help to maintain the facilities by, for example, doing the laundry and cleaning windows (figure 9). Another group, which could be characterized as "space-holders," included several individuals who often gathered in tandem with the rhythms of nature to celebrate the autumnal and vernal equinoxes.
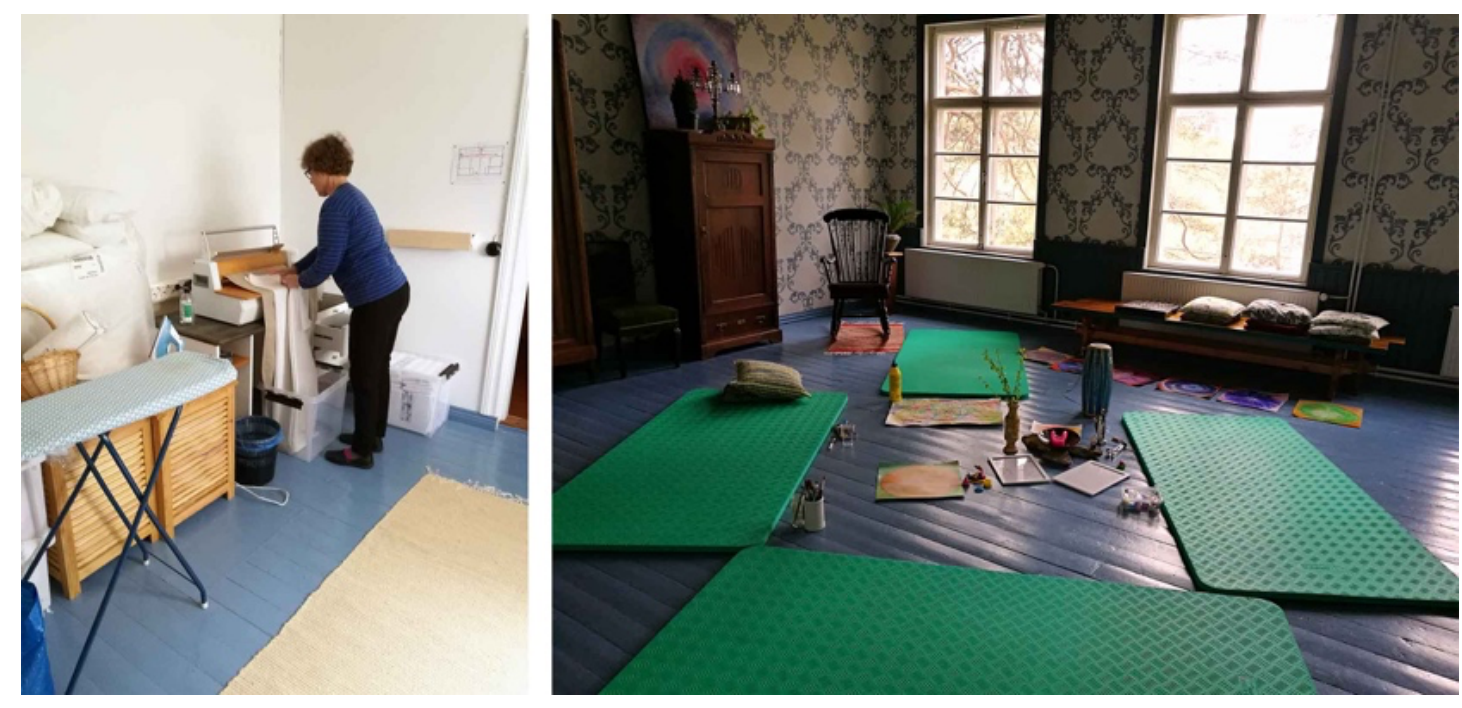

Figure 9: A volunteer helping with the laundry at Villa Sofia (left); Villa Sofia's hall, after the meeting of the space-holders group (right).

Because the members of this group regularly gathered in Villa Sofia's main hall, one influence on the local social field and the location's atmosphere became evident. ${ }^{4}$ Entrepreneur S described feedback from customers reporting special, uplifting experiences and sensations connected with the destination and its atmosphere. Accordingly, she experienced the gatherings of this group as constituent of and contributing to a "local group consciousness" (reflectivedialogue session, March 2019). She said of the social field that it "gathers the spirit and tone of the work done with the site and influences people who come here. It is a source from which they can draw." Entrepreneur S was not alone in these ideas. One way to describe the phenomenon of social fields and coconstruction of an atmosphere that can be sensed by others is to view it through the lens of similar reports. Jaworski (2011) has cited people's similarly uplifting experiences at other places regarded as special, such as Chartres Cathedral. In the context of this paper, such activities can be viewed as a conscious exercise of using different levels of attention to sense and bring to life a local social field. As

${ }^{4}$ See "cultivation of social fields" in Scharmer 2018 (p.14-15). In this context the idea of local social fields has connections to holding practices and experiences of working in a circle; see description of the Circle of Seven in Scharmer 2016 (pp. 151-155 and 175-179). 
characterized by Scharmer and Pomeroy (2019), social fields carry tones and qualities that reflect the tones and qualities of the inner dimension of the people who created them.

\section{Discussion and Conclusions}

This paper examines what new ways of becoming with the world while also exploring alternative ways of living with the Earth (see UNESCO, 2020) might look like in practice. The guiding question here is how the inner abilities of moving between different levels of attention affect the formation of the visible outcomes-actions and practices - and thus the emergence of the new. The question is inspired by the idea that form follows consciousness (Scharmer, 2018, 2016); in other words, the source conditions of individuals in social systems determine the qualities of people's actions and thereby the practical results of that system. This paper is focused in particular on following how the intention of the case study and the aim of prototyping a new future work and service culture grounded in care and awareness-based co-creation emerged in various forms. The analytical lenses generated by the constructive design research process provided an opportunity to map where the inner movement between levels of attention manifested itself in the process.

One finding is that people can develop the ability to practice vertical alignment in encounters with others, both humans and non-humans. More specifically, they are able to align with the inner posture of heart intelligence in encounters with customers and co-workers, and thus pay attention to how events and atmospheres unfold in the work and service cultures. Another finding is linked to the second analytical lens, the state of interconnectedness as described in the alignment practices associated with plant protection and the development of nature tourism services. These activities reflect the quality of the source conditions of the people involved, including the entrepreneurs, but also of the workshop participants. The effects of such alignment practices and how they can transition and influence other activities in the new culture were observed - for example, one course organizer reported experiences of alignment with nature during the course's activities. Similar visible manifestations of internal postures of trust and surrender were observed in the unfolding of the renovation process of Villa Sofia.

Some of the research findings describe the ability to move between different levels of attention in encounters, while others describe the application of the alignment practices in a workshop context. Some findings describe how the intention and guiding values of the case study became apparent in later stages of the process. The recruitment process and the emergence of a community are such examples and reflect the internal postures of the people involved and the way they operated from those postures. Customer feedback in both cases can be seen as a visible outcome of their activities and the collective source conditions.

The main contribution of this paper is to show how abstract concepts of alignment, such as moving between different levels of attention, were rendered 
visible and concrete in a case study context. The literature on care ethics was introduced to support the alignment and capacity-building concepts provided by Theory U. By laying out a real-world application that concretizes what such alignment with oneself, others, and the Earth could mean in practice, this paper addresses the identified research gap in empirical applications and complements the discussion in those fields' literature. Therefore, future projects undertaken in various disciplines interested in awareness-based transformation might find inspiration from the discussion and empirical stories presented here.

The current global pressure for change toward human and planetary sustainability requires a wide range of experiments and the creation of prototypes that gather information on how humanity can move toward flourishing and life-affirming futures. When we consider these prototypes of possible futures, even the more radical experiences and perspectives described through the analytical lenses-such as alignment with supportive life forces, synchronicities, social fields, or local group consciousness-should not be dismissed as too esoteric or mystical. On the contrary, they ought to be treated as inspirational opportunities to ask new questions so as to inform the next versions of the prototype (see Manzini, 2015). One might ask, for example, how can the culture, worldviews, and inner mindset and posture described in the existing prototype be further explored and made more accessible to a wider audience, and, thereby, more readily accepted in different contexts? Likewise, how could we move toward a state of greater pluralism, where, for instance, nurturing an ability to speak to the spirits of animals, building a capacity for heart intelligence, and exploring life forces that are larger than ourselves are seen as potential routes to solving problems? These are beneficial questions for future projects and further research.

\section{Acknowledgments}

This project has received funding from the European Union's Horizon 2020 research and innovation program under grant agreement No 870759. The content presented in this document represents the views of the authors, and the European Commission has no liability in respect of the content.

\section{References}

Aaltola, E. (2015). Wilderness experiences as ethics: From elevation to attentiveness. Ethics, Policy \& Environment, 18(3), 283-300. https://doi.org/10.1080/21550085.2015.1111614

Akama, Y. (2012). A "way of being": Zen and the art of being a human-centered practitioner. Design Philosophy Papers, 10(1), 63-80. https://doi.org/10.2752/089279312X13968781797634

Akama, Y. (2018). Surrendering to the ocean: Practices of mindfulness and presence in designing. In R. B. Egenhoefer (Ed.), The Routledge handbook of sustainable design (pp. 219-230). Routledge. 
Cunningham, D. (2018, June). Transforming Capitalism lab. Presencing Institute. https://www.presencing.org/\#/programs/live-sessions/transforming-capitalism-lablabor.

du Plessis, H. (2015). The mindset and posture required to engender life-affirming transitions [Conference presentation]. Transition Design Symposium. Pittsburgh, PA, United States.

https://www.academia.edu/28391321/The_Mindset_and_Posture_Required_to_Engen der_Life-\%20Affirming_Transitions.

Eriksen, M. A. (2012). Material matters in co-designing: Formatting \& staging with participating materials in co-design projects, events \& situations. Faculty of Culture and Society, Malmö University.

Hakio, K., \& Mattelmäki, T. (2019). Future skills of design for sustainability: An awareness-based co-creation approach. Sustainability, 11(19), paper 5247. https://doi.org/10.3390/su11195247

Halse, J., Brandt, E., Clark, B., \& Binder, T. (2010). Rehearsing the future. Danish Design School Press.

Hankivsky, O. (2004). Social policy and the ethic of care. UBC Press.

Haraway, D. J. (2016). Staying with the trouble: Making kin in the Chthulucene. Duke University Press.

Irwin, T. (2015). Transition design: A proposal for a new area of design practice, study, and research. Design and Culture, 7(2), 229-246. https://doi.org/10.1080/17547075.2015.1051829

Jaworski, J. (2011). Synchronicity: The inner path of leadership. Berrett-Koehler.

Jaworski, J., Kahane, A., \& Scharmer, C. O. (2004). The presence workbook. Society for Organizational Learning.

Kohn, E. (2013). How forests think: Toward an anthropology beyond the human. University of California Press.

Koskinen, I., Zimmerman, J., Binder, T., Redstrom, J., \& Wensveen, S. (2011). Design research through practice: From the lab, field, and showroom. Elsevier.

Krogh, P. G., \& Koskinen, I. (2020). Drifting by intention: Four epistemic traditions from within constructive design research. Springer Nature.

Macy, J., \& Brown, M. (2014). Coming back to life: The guide to the work that reconnects. New Society Publishers.

Manzini, E. (2015). Design, when everybody designs: An introduction to design for social innovation. MIT Press.

Mol, A. (2008). The logic of care: Health and the problem of patient choice. Routledge.

Puig de la Bellacasa, M. (2010). Ethical doings in naturecultures. Ethics, Place and Environment, 13(2), 151-169. https://doi.org/10.1080/13668791003778834

Puig de la Bellacasa, M. (2012). Nothing comes without its world: Thinking with care. The Sociological Review, 60(2), 197-216. https://doi.org/10.1111/j.1467954X.2012.02070.x

Puig de la Bellacasa, M. (2017). Matters of care: Speculative ethics in more than human worlds. University of Minnesota Press.

Scharmer, O. (2016). Theory U: Leading from the future as it emerges: The social technology of presencing (2nd ed.). Berrett-Koehler. 
Scharmer, O. (2018). The essentials of Theory U: Core principles and applications. Berrett-Koehler.

Scharmer, O. (2019, April 16). Vertical literacy: Reimagining the 21st-century university. Medium. https://medium.com/presencing-institute-blog/vertical-literacy-12-principlesfor-reinventing-the-21st-century-university-39c2948192ee.

Scharmer, O. (2020). Social systems as if people mattered: Response to the Kühl critique of Theory U. Journal of Change Management, 20(10), 322-332. https://doi.org/10.1080/14697017.2020.1744884

Scharmer, O., \& Pomeroy, E. (2019, October 29). Social field resonance: How to research deep structures of the social system. Medium. https://medium.com/presencinginstitute-blog/social-field-resonance-how-to-research-deep-structures-of-the-socialsystem-544d68654abf.

Schön, D. (1983). The reflective practitioner: How professionals think in action. Basic Books.

Seager, W. (Ed.) (2020). The Routledge handbook on panpsychism. Routledge.

Senge, P. M., Scharmer, C. O., Jaworski, J., \& Flowers, B. S. (2004). Presence: Human purpose and the field of the future. Society for Organizational Learning.

Tronto, J. (1993). Moral boundaries: A political argument for an ethic of care. Routledge.

Tronto, J. (2013). Caring democracy: Markets, equality and justice. NYU Press.

Tronto, J. (2017). There is an alternative: Homines curans and the limits of neoliberalism. International Journal of Care and Caring, 1(1), 27-43. https://doi.org/10.1332/239788217X14866281687583

UNESCO (2020). Learning to become with the world: Education for future survival (background paper for the Futures of Education initiative). Common Worlds Research Collective.

https://unesdoc.unesco.org/ark:/48223/pf0000374032?fbclid=IwAR0YU-sJserzEoHPvk RHkYAYO1Eq_nyFjHmcH8Em0n4KJx0BZib4hP5bk8A.

Yeandle, S., Chou, Y.-C., Fine, M., Larkin, M., \& Milne, A. (2017). Care and caring: Interdisciplinary perspectives on a societal issue of global significance. International Journal of Care and Caring, 1(1), 3-25. https://doi.org/10.1332/239788217X14866278171183

Zylstra, M. J., Knight, A. T., Esler, K. J., \& Le Grange, L. L. (2014). Connectedness as a core conservation concern: An interdisciplinary review of theory and a call for practice. Springer Science Reviews, 2(1-2), 119-143. https://doi.org/10.1007/s40362014-0021-3 


\section{Annex}

\begin{tabular}{|c|c|c|c|c|c|}
\hline & ACTIVITY & METHOD & DATA/MATERIAL & STAKEHOLDERS & OUTCOMES \& IMPACT \\
\hline$\star$ & $\begin{array}{l}\text { Four on-site visits for } \\
\text { contextual studies }\end{array}$ & $\begin{array}{l}\text { Exploratory fieldwork with } \\
\text { observations, } \\
\text { conversations, and } \\
\text { sensing of the space }\end{array}$ & $\begin{array}{l}\text { Field notes } \\
\text { Photos } \\
\text { Video recordings }\end{array}$ & $\begin{array}{l}\text { The island, nature, non-humans } \\
\text { Entrepreneur couple } \\
\text { (Seasonal) employees and } \\
\text { renovators } \\
\text { Visitors } \\
\text { One or two design researchers }\end{array}$ & $\begin{array}{l}\text { Research material for the workshops and } \\
\text { sense-making, as well as for overall } \\
\text { understanding }\end{array}$ \\
\hline s & Six unofficial visits & Spending time in the place & $\begin{array}{l}\text { Field notes } \\
\text { Photos }\end{array}$ & $\begin{array}{l}\text { One design researcher } \\
\text { The island, nature, non-humans, } \\
\text { and the entrepreneur couple } \\
\text { Visitors }\end{array}$ & $\begin{array}{l}\text { Personal experience of the place and a contribution } \\
\text { to overall understanding }\end{array}$ \\
\hline 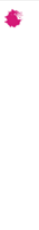 & $\begin{array}{l}\text { Three workshops held at } \\
\text { university premises } \\
\text { for co-creating new } \\
\text { openings for the business } \\
\text { and for local collaboration } \\
\text { Research motivation: } \\
\text { experimenting with the } \\
\text { theme of self-awareness }\end{array}$ & $\begin{array}{l}\text { Co-design } \\
\text { Materials for making, telling, and } \\
\text { enacting } \\
\text { Self-awareness techniques: } \\
\text { Guided moment of mindfulness, } \\
\text { writing lists of preoccupying } \\
\text { thoughts, and visual aids for } \\
\text { becoming aware of and scanning } \\
\text { one's inner state of being } \\
\text { Group reflection }\end{array}$ & $\begin{array}{l}\text { Material co-created by the } \\
\text { participants } \\
\text { Photos } \\
\text { Video recordings } \\
\text { Field notes }\end{array}$ & $\begin{array}{l}\text { Thirty stakeholders invited by } \\
\text { the entrepreneurs, including } \\
\text { customers, seasonal employees, } \\
\text { collaborators, and other local } \\
\text { entrepreneurs } \\
\text { Two design researchers }\end{array}$ & $\begin{array}{l}\text { Rich material for further development and } \\
\text { experimentation with a unifying encounter and } \\
\text { nature being central themes in all of the concepts } \\
\text { Co-creation of ideas in the context of social } \\
\text { innovation for which funding was sought on several } \\
\text { occasions in } 2017^{*} \text { ( e.g., a rehabilitation camp for } \\
\text { marginalized young people and lonely elderly } \\
\text { people, in collaboration with local stakeholders } \\
\text { and the municipality) (see Hakio \& Mattelmäki, 2019) }\end{array}$ \\
\hline 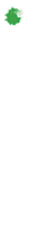 & $\begin{array}{l}\text { Two on-site workshops } \\
\text { on the island for } \\
\text { co-creating with non-humans } \\
\text { and nature } \\
\text { Research motivation: } \\
\text { Experimenting with the } \\
\text { concept of interconnectedness }\end{array}$ & $\begin{array}{l}\text { Co-design } \\
\text { Co-sensing exercises: } \\
\text { Guided moment of mindfulness, } \\
\text { walking meditation, and } \\
\text { embodied exploration in free } \\
\text { form to let the place talk back } \\
\text { Speculative role-taking exercise } \\
\text { Group reflection }\end{array}$ & $\begin{array}{l}\text { Material co-created by the } \\
\text { participants } \\
\text { Photos } \\
\text { Audio recordings } \\
\text { Field notes }\end{array}$ & $\begin{array}{l}\text { First workshop, with seven } \\
\text { random volunteers who were } \\
\text { visiting, recruited by the } \\
\text { entrepreneurs } \\
\text { Second workshop, with sixteen } \\
\text { people invited by the } \\
\text { entrepreneurs from their } \\
\text { social-media networks } \\
\text { One design researcher }\end{array}$ & $\begin{array}{l}\text { Workshop 1: Map (sketch) of specific areas and } \\
\text { places on the island's nature trail. Participants reflec- } \\
\text { ted on their role as humans and what it means } \\
\text { to co-create with nature and non-humans. } \\
\text { Workshop 2: Participants reflected on the experien- } \\
\text { ce of inner movement of taking roles. They explored } \\
\text { the becoming from the perspective of otherness. } \\
\text { These activities related to sensing from the whole } \\
\text { and exploring with the concept of interconnected- } \\
\text { ness were potentially seen as actions of care } \\
\text { (see Hakio and Mattelmäki, 2019). }\end{array}$ \\
\hline 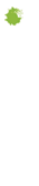 & $\begin{array}{l}\text { Two entrepreneur-led } \\
\text { workshops for applying the } \\
\text { participatory approach } \\
\text { in one's own process } \\
\text { Rehearsing future services } \\
\text { with international customers, } \\
\text { Camp school with local } \\
\text { primary school students }\end{array}$ & $\begin{array}{l}\text { Observation at the "Rehearsing } \\
\text { the Future" workshop } \\
\text { Co-designing the camp school } \\
\text { experience (secondary source) } \\
\text { Interviewing the entrepreneurs } \\
\text { afterward on the experience }\end{array}$ & $\begin{array}{l}\text { Audio recordings of the } \\
\text { interviews } \\
\text { Field notes } \\
\text { Photos (secondary source) }\end{array}$ & $\begin{array}{l}\text { Entrepreneur couple, two interna- } \\
\text { tional friends playing customers, } \\
\text { a local municipal official, } \\
\text { an apprentice trainee, and } \\
\text { a design researcher } \\
\text { Sixth-graders at a local primary } \\
\text { school and their teachers }\end{array}$ & $\begin{array}{l}\text { The entrepreneur couple applying the participatory } \\
\text { method and approach with their potential customers. } \\
\text { Experimenting with role-playing and props for future } \\
\text { services at the Villa Sofia (the school was under } \\
\text { renovation), as well as nature-tourism services for } \\
\text { international customers. } \\
\text { The findings were utilized in the implementation of } \\
\text { the service experiments. }\end{array}$ \\
\hline$\star$ & $\begin{array}{l}\text { Five entrepreneur-led } \\
\text { experiments for prototyping } \\
\text { ideas developed in the } \\
\text { previous workshops and } \\
\text { through the process } \\
\text { Camp school (2017) } \\
\text { Island wedding concept (2017) } \\
\text { Yurt accommodation concept } \\
\text { Building a community } \\
\text { New recruitment process (2018) } \\
\text { (see Hakio \& Mattelmäki, 2019) }\end{array}$ & $\begin{array}{l}\text { Observation at camp school, } \\
\text { yurt accommodation concept } \\
\text { and community-building } \\
\text { Island wedding concept, and } \\
\text { new recruitment process } \\
\text { (secondary sources) } \\
\text { Interviewing the entrepreneurs } \\
\text { afterward on the experiences }\end{array}$ & $\begin{array}{l}\text { Audio recordings of the } \\
\text { interviews } \\
\text { Field notes } \\
\text { Photos (secondary source) }\end{array}$ & $\begin{array}{l}\text { Sixth-graders at a local primary } \\
\text { school and their teachers } \\
\text { Customers using the new } \\
\text { nature-tourism services } \\
\text { Twelve new seasonal employees } \\
\text { (new recruitment process) } \\
\text { Facebook group for } 60 \text { people } \\
\text { invited by entrepreneurs from } \\
\text { their networks, both like-minded } \\
\text { people and local collaborators }\end{array}$ & $\begin{array}{l}\text { Some of the experiments remaining in } \\
\text { single-instance form (camp school and wedding } \\
\text { concept), while others continue (yurt taccommo- } \\
\text { dation and community-building). Via the new } \\
\text { recruitment process, group of seven young seasonal } \\
\text { employees co-created and implemented } \\
\text { a culture and community based on care, solidarity, } \\
\text { friendship and self-organization. Without restrictive } \\
\text { mental models from previous jobs, they created } \\
\text { practices from their own internal vision. } \\
\text { The caring atmosphere was transmitted also to cus- } \\
\text { tomers and spawned positive feedback and praise. }\end{array}$ \\
\hline 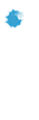 & $\begin{array}{l}\text { Collecting the local news } \\
\text { articles on the place, Facebook } \\
\text { posts, and the Elisaari website's } \\
\text { updates for following the } \\
\text { co-evolution of the place }\end{array}$ & Desk research & $\begin{array}{l}\text { Field notes } \\
\text { Archived online material }\end{array}$ & $\begin{array}{l}\text { Indirectly, the } \\
\text { entrepreneur couple, } \\
\text { customers using the } \\
\text { nature-tourism services, and } \\
\text { the local community }\end{array}$ & $\begin{array}{l}\text { Research material for the sense-making phases, } \\
\text { as well as for overall understanding }\end{array}$ \\
\hline 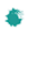 & Three phone conversations & Reflective dialogue & Field notes & $\begin{array}{l}\text { One entrepreneur alongside } \\
\text { a design researcher }\end{array}$ & $\begin{array}{l}\text { Research material for the funding applications (2017), } \\
\text { as well as for overall understanding }\end{array}$ \\
\hline$\star$ & $\begin{array}{l}\text { Nine on-site reflective dialogue } \\
\text { sessions }\end{array}$ & $\begin{array}{l}\text { Reflective dialogue } \\
\text { Presencing exercises }\end{array}$ & $\begin{array}{l}\text { Audio recordings and } \\
\text { visualizations of the process } \\
\text { Field notes } \\
\text { Photos }\end{array}$ & $\begin{array}{l}\text { One or two entrepreneurs } \\
\text { and a design researcher }\end{array}$ & $\begin{array}{l}\text { Significant part of the process for jointly making } \\
\text { sense of the overall process, bringing to the surface } \\
\text { deeper meanings, and discovering central themes } \\
\text { Seeds for creating the analytical lenses }\end{array}$ \\
\hline 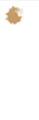 & $\begin{array}{l}\text { Two on-site sense-making } \\
\text { sessions }\end{array}$ & $\begin{array}{l}\text { Collaborative sense-making } \\
\text { activities } \\
\text { Materials for making such as play } \\
\text { sand, play-dough, plastic pieces, } \\
\text { markers, and paper }\end{array}$ & $\begin{array}{l}\text { Materials co-created in the } \\
\text { session } \\
\text { Photos } \\
\text { Audio recordings } \\
\text { Field notes }\end{array}$ & $\begin{array}{l}\text { One entrepreneur } \\
\text { with a design researcher }\end{array}$ & $\begin{array}{l}\text { Significant part of the process for jointly making } \\
\text { sense of the overall process, bringing to the surface } \\
\text { deeper meanings, and discovering central themes }\end{array}$ \\
\hline - & $\begin{array}{l}\text { One sense-making session on } \\
\text { university premises (2018) }\end{array}$ & $\begin{array}{l}\text { Exploring the collected material } \\
\text { together }\end{array}$ & $\begin{array}{l}\text { Video recordings } \\
\text { Field notes } \\
\text { Photos }\end{array}$ & $\begin{array}{l}\text { Entrepreneur couple and } \\
\text { two design researchers }\end{array}$ & Seeds for creating the analytical lenses \\
\hline
\end{tabular}

* Separately from research project, the entrepreneurs worked to cooperate with the local municipality in the field of social innovation. They have also applied for funding from various sources to build local collaborations and networks.

In 2020, they received funding to build a nature-tourism concept related to the Kalevala (the national epic of Finland) and undertake cooperative endeavors with local entrepreneurs and stakeholders.

Figure 10: Elisaari project data 